\title{
Enhancement of Dynamic Performance of Transmission Line using Static Synchronous Series Compensator
}

\author{
Muhammad Ali ${ }^{1}$, Prof. Dr. Naeem Arbab $^{2}$, Muhammad Daniyal ${ }^{3}$ \\ ${ }^{1,2,3}$ USPCAS-E, University of Engineering \& Technology, Peshawar. \\ engr.muhammadali78@yahoo.com ${ }^{1}$, mnarbab@yahoo.com ${ }^{2}$,engr.daniyal11@gmail.com ${ }^{3}$ \\ Received: 16 April, Revised: 26 April, Accepted: 30 April
}

\begin{abstract}
Static synchronous series compensator (SSSC) belongs to the facts family. It controls the flow of power in transmission line. The SSSC is a voltage source inverter connected in series with the transmission line and injects the voltage in quadrature with line current. Demand of power is growing day after day. Installation of new transmission lines is difficult because of environmental factors. The power flow capacity of existing transmission line has to be increased which is done by using compensation devices. The main reason behind poor performance of transmission system is the power flow capacity of existing transmission line under dynamic situations subjected to disturbances. FACTS technology opens new opportunities for controlling power and increases the usable capacity. It enhances corresponding power to flow through such lines under normal and contingency conditions. Recently new advancement in FACTS technology has introduced devices for reactive power compensation.
\end{abstract}

In this paper, a case study is discussed and test system is simulated in MATLAB/Simulink under normal conditions and also under fault conditions to improve the transient stability of the system. A $132 \mathrm{kv}$ transmission line coming from Kohat grid station to tall grid station has been selected as a test system which is suspected to overloaded conditions due to which voltage stability could not be maintained especially during the months of June, July and August. Static synchronous series compensator (SSSC) is installed near the Kohat bus. The results of current, voltage, active power and reactive power have been analysed with and without SSSC in the test system. Results shown that the stability of power system, voltage profile and power flow capability enhances by using SSSC. Also by using SSSC the oscillations were damped very quickly as compared to the circuit without using SSSC and the stability is maintained.

Keywords-Flexible Alternating Current Transmission System (FACTS), Static Synchronous Series Compensator (SSSC), MATLAB/Simulink Software, Per Unit (Pu), Peshawar Electric Supply Company (PESCO).

\section{INTRODUCTION}

The modern power system covers a large area, and has a large number of buses, load and generators. In addition, the production plants available are often not close to the load centers and therefore power must be transmitted over long distances. To respond to the day by day increasing electrical load and industrialization new lines should be added to the system to fill the gap between generation and consumption, but because of the cost, the installation of new lines is mostly restricted [1]. Therefore, power system companies are forced to rely on the infrastructure already existing instead of constructing new transmission lines. In order to maximize the efficiency of production, transport and distribution of electrical energy, the transmission networks are very often pushed to their thermal and physical limits, which cause power disruption and individual power outages and could lead to failure of the entire system. With such an increased stress on the transmission lines of existing system, use of different methods of compensation becomes important [2].

Electric power system ability to damp system oscillation after occurrence of major fault is called stability of power system. After the occurrence of fault, there is disturbance in power system until the oscillations are damped out. Any change in voltage or frequency in AC power system leads to disturbance [3]. Part of the system where fault has occurred should be disconnected to avoid system break down. Eventually to avoid whole system break down or disturbance in system, voltage and frequency should be observed and controlled accurately. A very common type of fault is short circuit fault which restrain the voltage of grid thus causing oscillations by disturbing the rotating machines in jurisdiction of fault. In order to avoid system instability these oscillations need to be damped out. Voltage stability, frequency stability and inter area stability are of major concern in AC electric power system [4]. When electric power system does not fulfill the demand of reactive power, voltage instability is caused. Healthy voltage profile must be maintained and must constantly be delivered to load. But there is always a diversity factor i.e. variation in demand time to time so power system's reactive power demand also changes that is the reason why voltage instability is caused in power system which effects the quality of power transmitted.

\section{A. Flexible Alternating Current Transmission System}

The long established techniques for solving these difficulties; usually we use mechanically and fixed switched shunt and series capacitors, synchronous generators and 
reactors. Due to slowly response, damage of mechanical components, derived response has not been effective. Power electronic converters are created with the innovation of Thyristor devices. It is based controller that provides unwrinkled, continues, at a great rate and able to be done again performance for control of power system. FACTS family is an implementation of power electronic devices to electrical transmission systems. FACTS are AC transmission systems that Composed of other static controllers and power electronic controller. Current rating has enhanced to larger values for Thyristor in the last years. It made power electronics able and thousands MW high power applications.

FACTS devices has their speed and resilience are capable to supply the transmission system with a few benefits. Examples are Transient stability enhancement, voltage stability and control, power oscillation damping. The chosen device sort and rating and the specific voltage level, a transmission capability improvement of up to $40 \%$ to $50 \%$ may be obtained by FACTS elements. Now days the fundamental abstractions to the integration of these promising innovations are Cost, complexity and reliability issues.

FACTS technologies give solutions to today's power system. It increases power flow transfer capability. It also enhances voltage profile continues control, enhancing damping of system, minimizing losses etc. FACTS devices has its real time operating control with high power electronics based equipment. FACTS controllers two groups which is based upon various technical methods, resulting in controllers capable to solve transmission problems [5].

\section{B. Static Synchronous Series Compensator (SSSC)}

The static synchronous series compensator (SSSC) is a series device of the Flexible AC Transmission Systems (FACTS) family using power electronics to control power flow and improve transient stability on power grids. In place of using capacitor and reactor banks, a SSSC use self-commutated voltage-source switching converters to synthesize a three-phase voltage in quadrature with the line current. The main interest is to use the SSSC for controlling flow of power (active and/or reactive) in transmission lines, whereas the SSSC is mainly recommended for damping electromechanical oscillations. Thus, the SSSC control system may be made by a compensation control loop, to accomplish its steady-state function, and by a fast response control, to act during electromechanical transients [6].

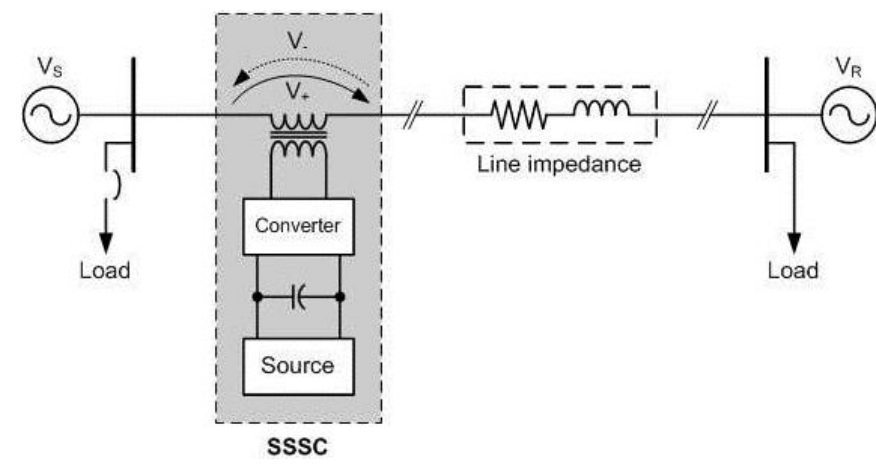

Figure 1. Static synchronous series compensator (SSSC) [6]

\section{RELATED WORK}

The long transmission lines connected to the weak grid system will result in system instability. Work has been done to enhance the transmission line flow limits and the system stability. The first swing and subsequent stability limit of oscillation of a system with SSSC and STATCOM is discusses in [7] one at a time. In both cases the stability of the system was greatly increased. STATCOM improved first swing limit of stability more affectively shown by Results, however in the subsequent swings SSSC was more affective. This paper is deficient in system response in Transient condition.

Moreover, in [8] the some technical issues that include sub synchronous resonance, protective equipment's and reliability of capacitors are discussed. Traditionally used series capacitor could not eliminate these technical problems, so a new series compensation device called static synchronous series compensator was used in transmission line to remove those problems, that device consist of synchronous voltage source, voltage source converter employing IGBT or gate turn off relying upon power requirements. The basis for superior operation and performance of static synchronous series compensator was proffered by voltage source nature.

About real and reactive power to enhance the amount of power delivered by the transmission line, authors also discussed [9] about compensation methods. Performance of power system is made better by using series compensation technique which enhances the power flow. In future some more wok can be done in this paper to model SSSC in such a way to control true power and reactive power flow in the system.

The SSSC were brought in contact with electrical parameters of the line in paper [10]. It was straight forward from the results that PI and PID (fuzzy logic controlled devices) provided by FACTS family (SSSC) has developed method used for control to great extent.

The requirement of real and reactive power flow in the transmission line for the reason of compensation and increase of the capacity of power transferred by a line when IPF Controller acted as standalone as SSSC. In this paper [11] a test case was presented and from the numerical results performance and eligibility of compensation device on transmission line was demonstrated.

The SSSC was modeled and simulated in research paper [12], SSSC inserted voltage is sinusoidal and variable in magnitude is shown from result. The inserted volts are in phase quadrature with the transmission line amps. The line is in series with the capacitive reactance and inductive reactance. The operation and working of a novel control scheme designed both for SSSC and STATCOM described by the Authors in [13]. The scheme was based on a design which composed of 48pulse GTO voltage source inverter. Authors studied voltage stability and compensation of reactive power in the electric grid network. The designed scheme containing SSSC and STATCOM in the power system was simulated and complete digital simulation was performed.

Phase-lead characteristics are provided by 2 stage block in paper [14], for the compensation of the output signals which 
lag behind the input signal. Block three is a high pass filter also called wash out block. Volts Vabc and amps Iabc respectively are taken as input by power oscillation damping controller and are converted into power. The switch remains unclosed when the fault does not occur but when fault occurs then the switch closes. An error signal is produces after the oscillations are damped out, and at the end both error signals are added.

Two area 11-bus test systems is used in paper [15], so we have two areas which are zone-1 and zone-2, these are used to check the efficiency of the series compensator, the FACT family device which is used for series compensation is static synchronous series compensator, it is connected between bus- 9 and bus-10. Volts sources of (13.8) kilo Volts are attached to a (290) kilo meter line with the help of three-phase transformer, this step up transformer has an output voltage of 500KV and power in area-1 and area-2 are 1000MVA and 4200MVA respectively. Loads in both area- 1 and area- 2 are $30 \mathrm{KW}$ which are such designed that the true power flow on the line is from zone- 1 to zone-2. The true power and reactive power used by the connected load is a function of the system volts.

\section{PRINCIPAL OF SERIES COMPENSATION}

The voltage source $\mathrm{VC}$ is connected at the intermediate point of a transmission line. As shown in figure 2 represents an ideal series compensator.

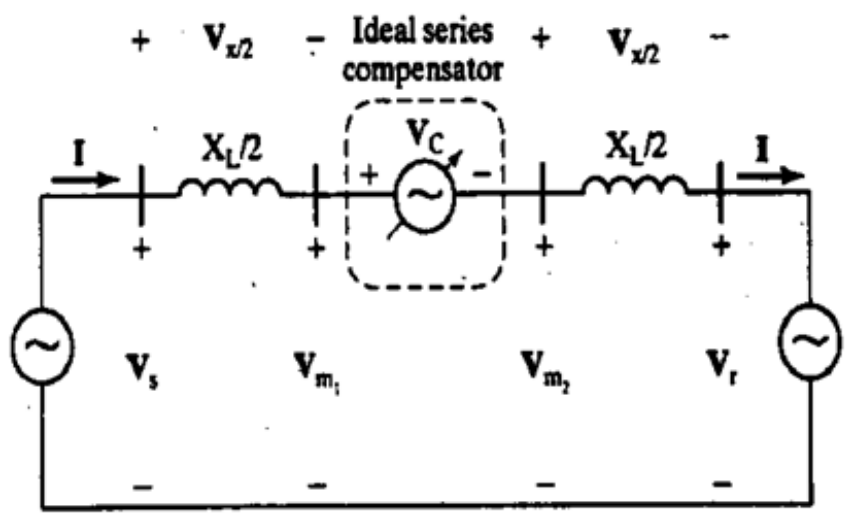

Figure 2. Ideal Series compensator in transmission line

In transmission line current flowing is given by:

$$
I=\frac{V s-V r-V c}{j X}
$$

Voltage source can only supply or absorb reactive power in transmission line as series compensator cannot supply or absorbed real power [4]. It is replaced by capacitive or inductive impedance shown in equation 3.3

$$
\text { Xeff }=\mathrm{X}-\mathrm{Xcomp}
$$

Xcomp represents inductive or capacitive impedance, $\mathrm{X}$ represents total impudence of transmission line Xeff represents the effective impedance. Current leads voltage by 90oinductive mode. Power is not absorbed/generated by the voltage source (VC) installed in inductive and capacitive modes. Capacitive mode of compensation is commonly used. Compensation cost for series capacitor is less than shunt capacitor. The cost per unit VAR of shunt capacitor is half as compared to series capacitor. Series capacitor rating will nearly be $10 \%$ of shunt capacitor rating [16].

\section{CONCEPT OF SERIES CAPACITIVE COMPENSATION}

Basic principle of series capacitive compensation is to decrease the overall series impedance of the line as shown in Equation 1, power is inversely proportional to impedance $(\mathrm{X})$, as overall impedance of the circuit decreasing power flow increases. In Figure 3 (a) series compensated line with two identical sections is represented. Magnitude of voltage across inductor is assumed to be equal. Let us suppose that magnitude of voltage across inductor for same end voltages is increased by the magnitude of the compensation voltage developed across series capacitor, resulting in an increase in transmission line current.

$$
\mathrm{P}=\mathrm{V} 2 \sin \delta / \mathrm{X}
$$

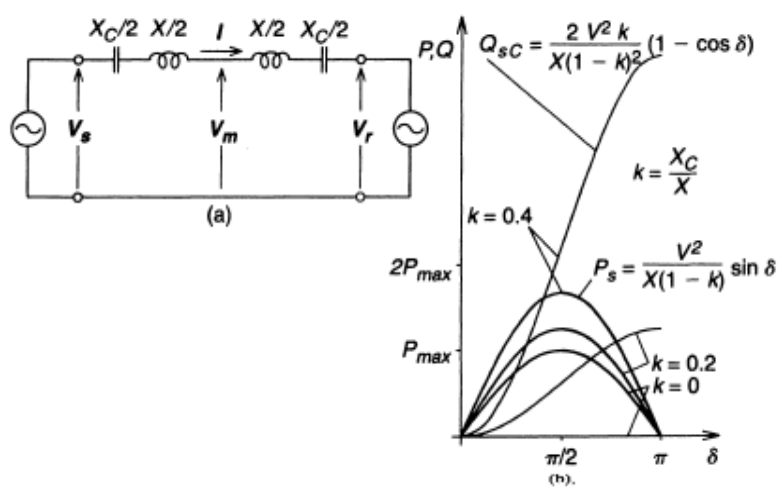

Figure 3. (a) Two machine power system with series capacitive compensation. (b) Real power and series capacitor reactive power vs angle characteristics

For series capacitive compensation Equation 4.3 becomes:

$$
\begin{gathered}
\mathrm{X}_{\mathrm{eff}}=\mathrm{X}-\mathrm{X}_{\mathrm{c}} \\
\text { Or } \\
\mathrm{X}_{\mathrm{eff}}=(1-\mathrm{k}) \mathrm{x} 0 \leq k<1 .
\end{gathered}
$$

In Equation 4.6 ' $\mathrm{K}$ ' shows the degree of compensation. Thus by changing $\mathrm{K}$ we can control the flow of power. After compensation the current equation is given in Equation 4.7.

$$
1=\frac{2 V}{(1-k)} \mathrm{x} \sin \frac{\delta}{2}
$$

The real power is given as:

$$
\mathrm{P}=\mathrm{V}_{\mathrm{ml}}=\frac{V^{2}}{1-K} \sin \delta
$$

The reactive power supplied by the series capacitor can be expressed as follows:

$$
\mathrm{Q}_{\mathrm{c}}=\mathrm{I}^{2} \mathrm{Xc}=\frac{2 V^{2} K}{X(1-k)^{2}} 1-\cos \delta
$$




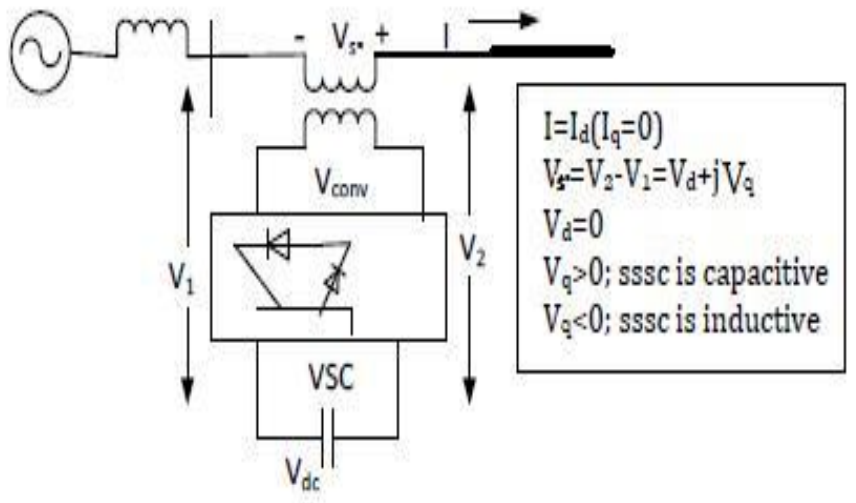

Figure 4. Connection of SSSC with transmission line [17]

Above figure. 4 shows how SSSC is connected with the transmission line in the power system, to connect SSSC in series with the transmission line coupling transformer is used, capacitor is connected on the DC side of the circuit and is kept charged by drawing small power from the system, the control block is DC to AC converter, it may be IGBT or GTO. Basic equation of power flow is given as:

$$
\begin{gathered}
\mathrm{P}=\frac{V_{s} V_{r}}{X L} \sin (\delta \mathrm{s}-\delta \mathrm{r})=\frac{V 2}{X L} \sin \delta \\
\mathrm{Q}=\frac{V s V r}{X L}\left(1-\cos \left(\delta_{\mathrm{S}}-\delta_{\mathrm{R}}\right)\right.
\end{gathered}
$$

SSSC has the ability of emulating a compensating reactance $\mathrm{Xq}$ (both inductive and capacitive) in series to the transmission line inductive reactance $\mathrm{XL}$, Therefore, the expressions for power flow becomes:

$$
\begin{gathered}
\mathrm{P}_{\mathrm{q}}=\frac{V^{2}}{X_{e f f}} \sin \delta=\frac{V^{2}}{X L\left(1-\frac{x_{q}}{X_{L}}\right)} \sin \delta \\
\mathrm{Q}_{\mathrm{q}}=\frac{V^{2}}{X_{\text {eff }}}(1-\cos \delta)=\frac{V^{2}}{X L\left(1-\frac{x_{q}}{X_{L}}\right)}(1-\cos \delta)
\end{gathered}
$$

The reactance of the transmission line between sending and receiving ends Xeff. In above equations, it also comprise of emulated variable reactance $\mathrm{Xq}$ inserted by the injected voltage source of the SSSC.

\section{MODELING OF CIRCUIT IN MATLAB}

A detailed model has been designed and developed in MATLAB/Simulink. The results of system with and without SSSC have been analyzed. The Model was selected from Kohat area as currently that area is facing the low voltage issues especially during peak load in month of June, July and August. Using SSSC we achieved an improved voltage profile, power flow and better transient stability of system.

\section{A. Case Study}

In this article the case study is Kohat, Gurguri and Tall $132 \mathrm{kV}$ grid station as shown in figure 5. During peak load especially in the month of June, July and August, the grid faces low voltage problems due to which the system become overloaded as shown in table 1. In transmitted power after occurrence of major faults the problem of Transient stability can become the limiting factor. To enhance the power transfer capability and to increase voltage stability during overloaded and fault conditions SSSC is installed near Gurguri grid station. By increasing the voltage stability at the consumer end, the possibilities of blackouts have been reduced in the mentioned area. Furthermore, the forced load shedding, which is considered as a big loss for the utility companies has been avoided.

Test system has been simulated in MATLAB/Simulink at overloaded conditions. The outputs have been analyzed for the test system with and without SSSC in the circuit as shown in figure 6 and figure 7 respectively.

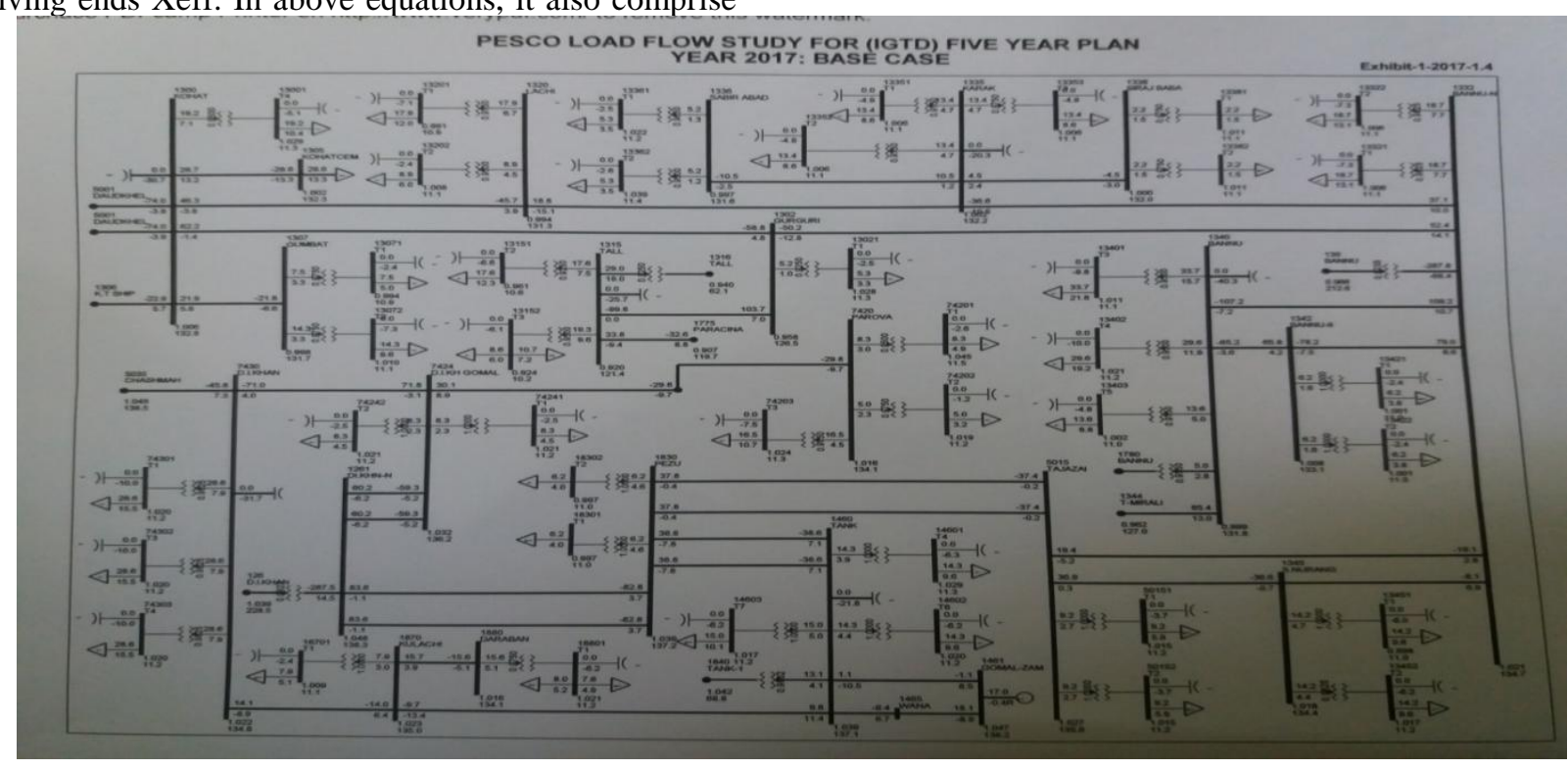

Figure 5. Test System 


\section{B. System without SSSC}

In this system Three-phase programmable voltage source is modeled as $132 \mathrm{kv}$ Kohat grid station here in MATLAB/Simulink. Configuration of which is shown below in figure 6 , Three buses are used in the test system i.e. Kohat
Bus, Gurguri Bus and Tall Bus which are modeled as Threephase V-I measurement. The transmission line between the grids is modeled by distributed line parameter block. The results are analyzed under overloaded condition.

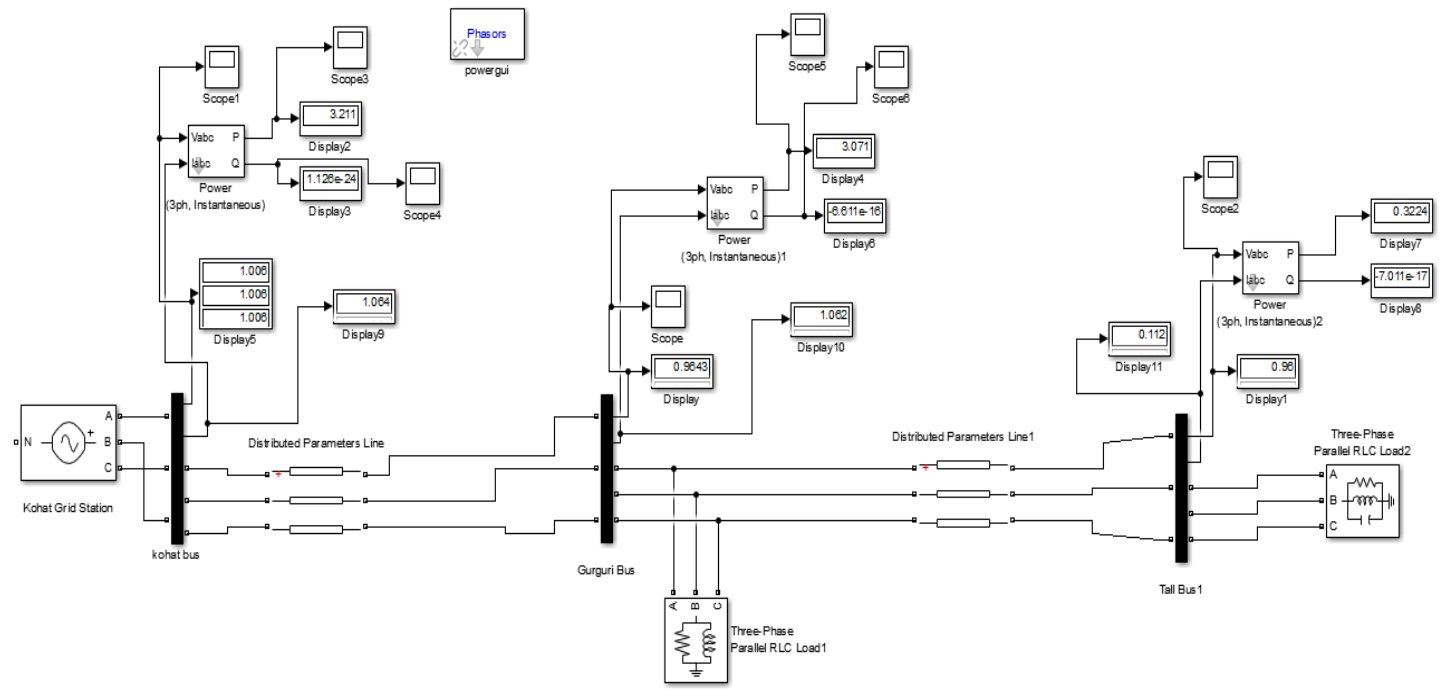

Figure 6. Simulink model of test system without using SSSC

\section{C. $\quad$ Syste using SSSC}

Now SSSC is installed near Kohat bus in $132 \mathrm{kv}$ transmission line coming from Kohat to Gurguri as shown in figure 7, as the line length is in range of medium transmission line so SSSC can be installed and used to fulfill the need of the test system. In Simulink test system is simulated with SSSC and the results are analyzed.

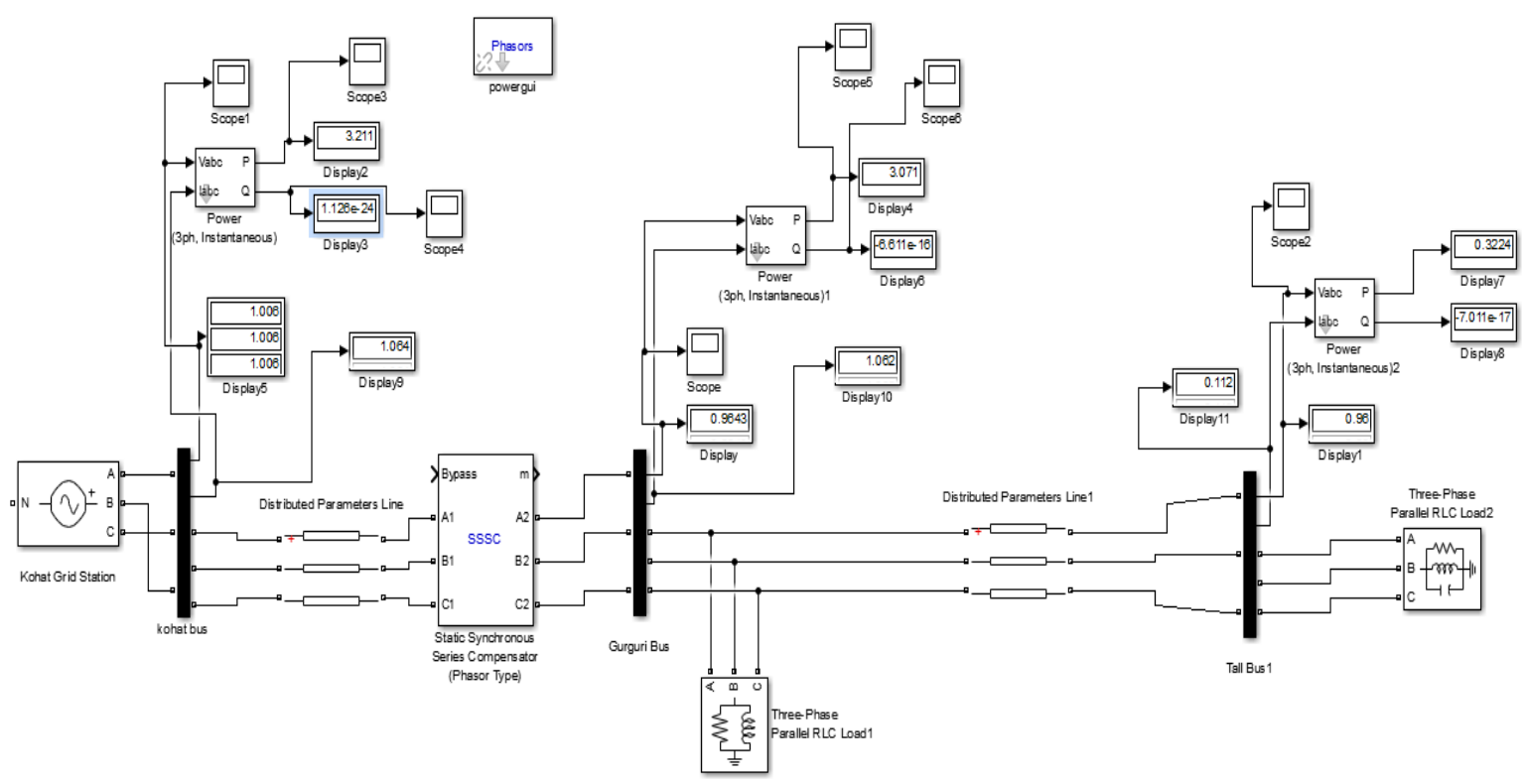

Figure 7. Simulink Model of test system using SSSC 


\section{Discussion on Results}

The results of simulation without SSSC are shown in Table 1. The below data is for the months of June, July and august in overloaded conditions at peak load. The data is in terms of different parameters consists of voltage (pu), current (pu), Active power (pu) and reactive power(pu) respectively. All these values are taken before the installation of SSSC at peak load. Test system is simulated with SSSC in MATLAB/Simulink and the results are shown in Table 2.The same parameters were again tested and analyzed on the same conditions after the installation of SSSC. The obtained data clearly shows that there is a significant increase in the values of voltage (pu), current (pu), Active power (pu) and reactive power (pu) after the installation of SSSC.

TABLE I. TEST SYSTEM WITHOUT SSSC AT PEAK LOAD

\begin{tabular}{|l|l|l|l|l|}
\hline Bus & $\begin{array}{l}\text { Voltage } \\
(\mathbf{p u})\end{array}$ & $\begin{array}{l}\text { Current } \\
(\mathbf{p u})\end{array}$ & $\begin{array}{l}\text { Active } \\
\text { Power }(\mathbf{p u})\end{array}$ & $\begin{array}{l}\text { Reactive } \\
\text { power }(\mathbf{p u})\end{array}$ \\
\hline Kohat bus & 1.008 & 1.021 & 1.202 & 0.9597 \\
\hline $\begin{array}{l}\text { Gurguri } \\
\text { Bus }\end{array}$ & 0.9425 & 1.035 & 1.208 & 0.8253 \\
\hline Tall Bus & 0.9180 & 0.1872 & 0.2011 & 0.1923 \\
\hline
\end{tabular}

TABLE II. TEST SYSTEM WITH SSSC AT PEAK LOAD

\begin{tabular}{|l|l|l|l|l|}
\hline Bus & $\begin{array}{l}\text { Voltage } \\
(\mathbf{p u})\end{array}$ & $\begin{array}{l}\text { Current } \\
(\mathbf{p u})\end{array}$ & $\begin{array}{l}\text { Active } \\
\text { Power (pu) }\end{array}$ & $\begin{array}{l}\text { Reactive } \\
\text { Power (pu) }\end{array}$ \\
\hline $\begin{array}{l}\text { Kohat } \\
\text { Bus }\end{array}$ & 1.064 & 1.064 & 3.211 & 2.972 \\
\hline $\begin{array}{l}\text { Gurguri } \\
\text { Bus }\end{array}$ & 0.9643 & 1.062 & 3.071 & 2.958 \\
\hline $\begin{array}{l}\text { Tall } \\
\text { Bus }\end{array}$ & 0.960 & 0.112 & 0.3224 & 0.1988 \\
\hline
\end{tabular}

It is clear from the results that voltage profile is improved at Kohat and Gurguri bus and the active and reactive power flow is enhanced. All the values are given in per unit and according to PESCO 0.95 pu in the healthy voltage limit below which the system gets overloaded. During peak loads the voltage level at Kohat and gurguri bus goes below healthy voltage limit thereby increasing current in the circuit which increases losses. Under these conditions the system becomes overloaded which lead to forced load shedding. In order to reduce these losses and increase the flow of power, series compensator SSSC is included in the system model simulation which shows that voltage profile is improved and goes above 0.95 per unit for both Kohat and Gurguri bus thus increase in flow of active and reactive power in the system.

Figure 8 and Figure 9 shows the result of active power and reactive power respectively for the test system without using SSSC.

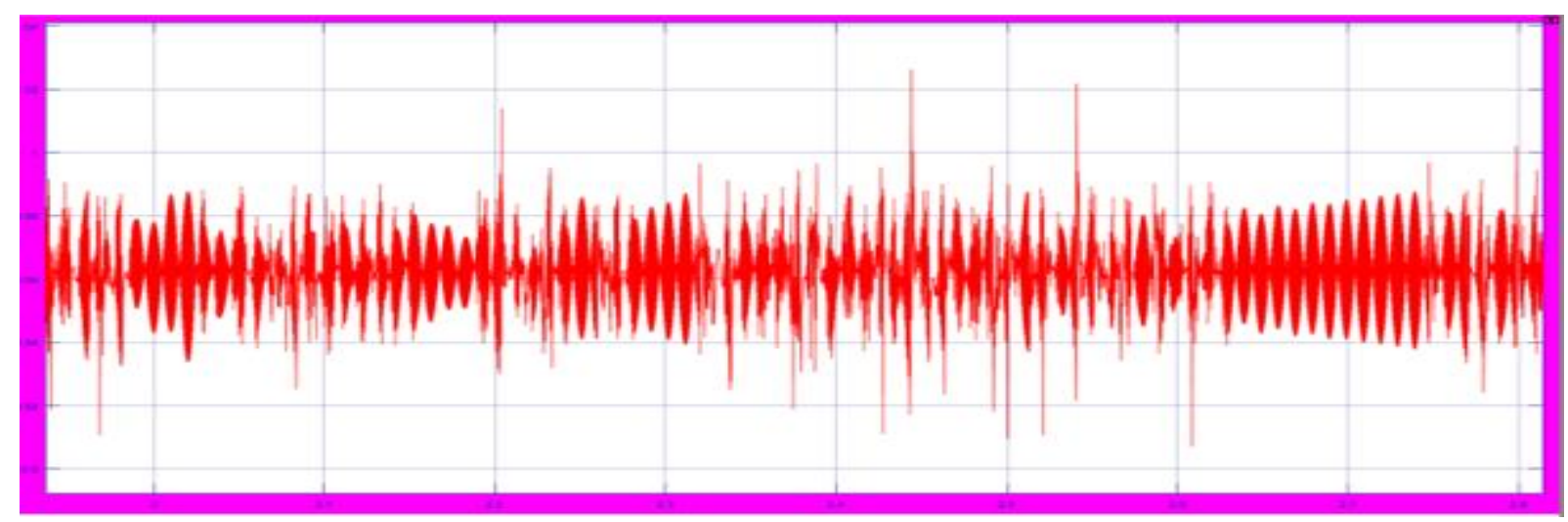

Figure 8. Reactive power flows in test system without using SSSC under overloaded condition

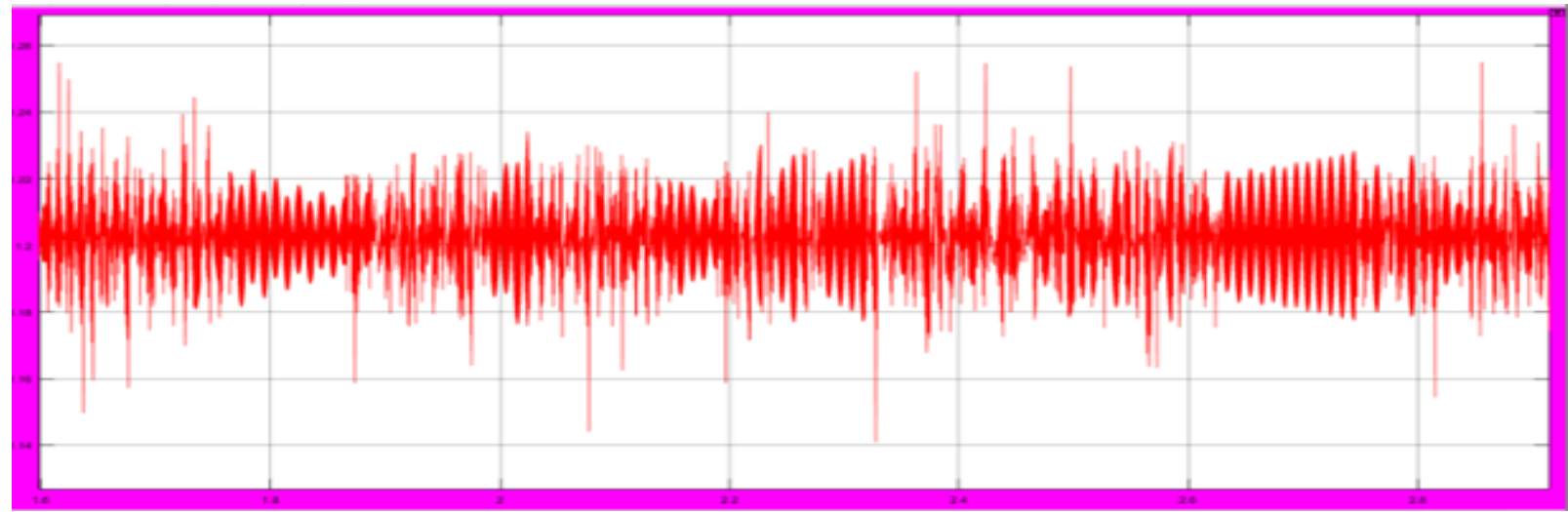

Figure 9. Active power flows in test system without using SSSC under overloaded condition 


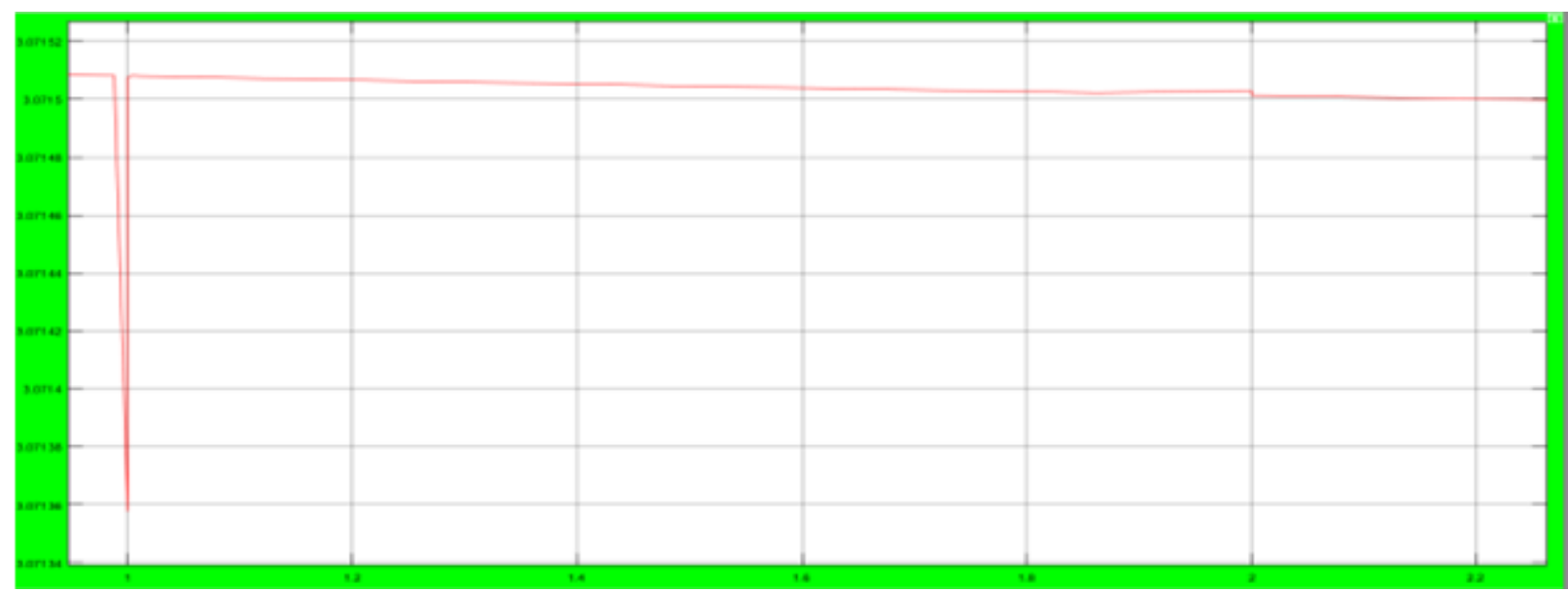

Figure 10. Active power flows in test system with using SSSC under overloaded condition

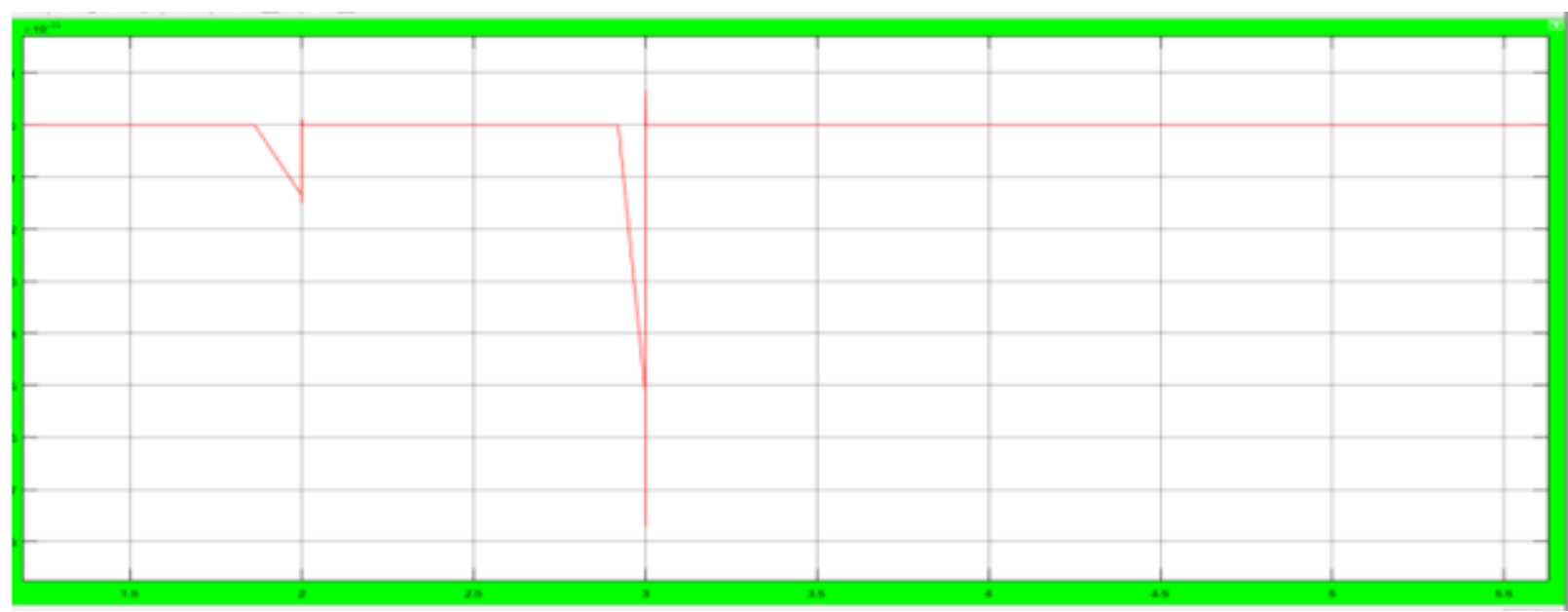

Figure 11. Reactive power flows in test system with using SSSC under overloaded condition

Figure 8 and figure 9 shows that during overload conditions oscillation go on increasing and the system destabilizes at the end which leads to force load shedding and due to this losses occur both to utility and customer.

Figure 10 and Figure 11 shows the result of active power and reactive power respectively for the test system with using SSSC.

After compensation techniques used, now in overloaded condition the series compensator provide reactive power to transmission line which increase the flow of active power in transmission line from generating station. in figure 8 and figure 9,the oscillation when rise up, the control system of SSSC detects and in milliseconds required voltage is provided which is in line qudrature with transmission line current and overall voltage level gets improved and system reaches to stability very quickly as can be seen in figure 10 and 11 a straight line after oscillation. Oscillations are damped very quickly and system becomes stable.

\section{ACKNOWLEDGEMENT}

This project consumed huge amount of work, research and dedication. Still, implementation would not have been possible if I did not have a support of Prof. Dr. Naeem Arbab, Engr. Muhammad Daniyal and PESCO. Therefore I would like to extend my sincere gratitude to all of them.

\section{CONCUSLION}

SSSC has recently become the most effective and important device for the compensation of reactive power in power system. Installation of the new transmission lines are generally not economical. Furthermore, it is also a very time consuming method due to which power flow can be interrupted and can be very costlier in the urban areas. SSSC becomes the only way left to increase the power flow and to improve voltage stability in an economical way. A case study has been selected from Kohat area which is in PESCO. There is a $132 \mathrm{Kv}$ transmission line coming from Kohat to Gurguri. During over loaded conditions voltage stability is not maintained especially during the months of June, July and august. Losses increases and force load shedding is usually carry out which is big loss to the power supply companies. In this research paper SSSC is used to achieve voltage stability and enhance power flow in the network. The test model is implemented in MATLAB/ Simulink for two different scenarios. In both the Scenarios, with and without SSSC, the result of current, voltage; active power and reactive power have been analyzed. In first portion 
test system was simulated in overloaded condition. After simulation results it was clear that voltage profile has been improved greatly by using SSSC in the circuit. Power flow capacity has also been enhanced using SSSC. In second portion the test system was simulated under a common three phase short circuit fault and the result shows that by using SSSC the oscillation was damped very quickly as compared to the circuit without using SSSC and the stability was also maintained. Even though the obtained model results were very satisfactory. But still there is room to improve the current model response. The static synchronous series compensator (SSSC) is capable of controlling the flow of power at a desired point on the transmission line by injecting a fast changing voltage in series with the line and it keeps the constant power flow under fault conditions. SSSC can be implemented on more complex networks in Pakistan in future. Voltage profile and power flow control will be examined in MATLAB/Simulink. Location of SSSC should be optimized for network through further studies of system. It might be possible to build a hierarchical control scheme in order to achieve better control of oscillations and, for example, optimization of power flow, especially in case of multiple contingencies. Future research in this direction would provide more insight into these possibilities.

\section{REFERENCES}

[1] Prof.R.M. Malkar, Prof.V.B.Magdum, "Recent Trends in Real and Reactive Power flow Control with SVC and STATCOM Controller for transmission line," IJAIEM, March 2016.

[2] M.Maheskumar, "A study of reactive power compensation in power system and its compensation techniques" International journal of innovations in engineering and technology, 2016.

[3] S.S.Patil, Manasa.N.R, P.Anaji, "Power Quality Improvement using SSSC" International Journal of Emerging Research in Management \&Technology, May 2016.

[4] Y.H.Song and A.T.Johns, "Flexible ac transmission systems (FACTS)," The Institution of Electrical Engineers 1999.

[5] N.G.Hingorani and L.Gyugyi, "Understanding FACTS: concepts and technology of flexible AC transmission systems," IEEE Press, 2000. B

[6] K S Apremeya, Veena "Voltage Profile Improvement of Transmission Line Using SSSC" International Journal of Scientific Development and Research (IJSDR) Volume 2, Issue 1 January 2017.

[7] M.H.Haque"Stability Improvement by Facts devices: A Comparison between STATCOM and SSSC'IEEEPower Engineering Society Meeting, 2005.

[8] G.Saraswathi, Dr.N.Visali, B.N.Reddy, "Power flow improvement using Static Synchronous Series Compensator (SSSC)" International Joural of Engineering Studies and Technical Approach.

[9] Sedighizadeh, M.Toulabi, M.S.Rezazadeh, A.Khatibi, "Damping Improvement by SSSC and STATCOM in a Part of Iran Electrical Network" $43^{\text {rd }}$ Universities Power Engineering International Conference, 2008.

[10] A.Haleem, R.Malgireddy, "Power Flow Control with Static Synchronous Series Compensator (SSSC)" Proc. of the International Conference on Science and Engineering (ICSE 2011)

[11] P.Dhoble, A.Bhandakkar, "Review of Active Reactive Power Flow Control Using Static Synchronous Series Compensator (SSSC)" INTERNATIONAL JOURNAL OF INNOVATIVE RESEARCH \& DEVELOPMENT, April, 2013.

[12] Zenk, H. Akpinar, A.S. "PI, PID and Fuzzy Logic Controlled SSSC Connected To a Power Transmission Line, Voltage Control Performance
Comparison" $4^{\text {th }}$ Intl Conference on Power Engineering, Energy and Electrical Drives, 2013.

[13] A.A.Nimje, C.K.Panigrahi and A.K.Mohanty, "Enhanced power transfer capability by using SSSC" Journal of Mechanical Engineering Research Vol. 3 (2), pp. 48-56, February 2011.

[14] Sen, K.K. "SSSC, Theory, Modeling and Application" IEEE Transactions on Power Delivery" (Volume: 13, Issue: 1) Pages 241 246.

[15] M.S.E.Moursi and A.M.Sharaf"Novel Controllers for the 48-Pulse VSC STATCOM and SSSC for Voltage Regulation and Reactive Power Compensation" IEEE TRANSACTIONS ON POWER SYSTEMS, VOL. 20, NO. 4

[16] Rizan A. Ali, Ergun Ercelebi "Improve Power Stability \& Damping Oscillation in Multi Machine System Using (SSSC) with POD Controller" International Journal of Computing, Communications \& Instrumentation Engineering (IJCCIE) Vol. 3, Issue 2 (2016).

[17] P. Dhoble, A. Bhandakkar "Active Reactive Power Flow Control Using Static Synchronous Series Compensator (SSSC)" IOSR Journal of Electrical and Electronics Engineering (IOSR-JEEE) e-ISSN: 22781676,p-ISSN: 2320-3331, Volume 7, Issue 6 (Sep. - Oct. 2013)

[18] S.S.Patil, Manasa.N.R, P.Anaji "Power Quality Improvement using SSSC" International Journal of Emerging Research in Management \&Technology ISSN: 2278-9359, May 2016

[19] M.Thangavel, S.Shiny Jasmine "Enhancement Of Voltage Stability And Power Oscillation Damping Using Static Synchronous Series Compensator With SMES" International Journal of Advanced Research in Technology Vol. 2 Issue 3, March 2012.

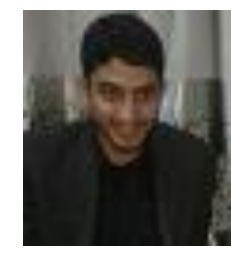

Muhammad Ali belongs to Peshawar, Pakistan. $\mathrm{He}$ is graduated from University of Engineering and Technology (UET) Peshawar as an Electrical Engineer in 2014. He has completed his MS Electrical Energy System Engineering from USPCAS-E, UET Peshawar and successfully defended his research thesis. 